\begin{tabular}{|l|l|l|l|l|l|l|}
\hline InterteXto & Uberaba & UFTM & $\begin{array}{l}\text { v. 2 } \\
\text { n. 3 }\end{array}$ & p. 14-35 & 2009- jan. / jun. & ISSN 1981-0601 \\
\hline
\end{tabular}

\title{
A AVALIAÇÃO DIANTE DAS NOVAS NECESSIDADES EDUCACIONAIS: RUPTURAS DE PARADIGMAS
}

\author{
THE EVALUATION FACING THE NEW EDUCATIONAL NEEDS: \\ PARADIGM RUPTURE
}

Irma Beatriz Araújo Kappel ${ }^{1}$

\section{Resumo}

Este artigo apresenta a aplicação de uma proposta de avaliação participativa em curso de Licenciatura em Letras e de uma pesquisa que investigou as opiniões dos alunos universitários a respeito dos pontos positivos e negativos dessa avaliação e quais os pontos que fazem com que uma apresentação do aluno seja considerada boa ou ruim. A pesquisa, desenvolvida segundo as orientações do enfoque qualitativo, teve por objetivo fundamental identificar, caracterizar e analisar os significados e as práticas de avaliação da aprendizagem, segundo a perspectiva de alunos do ensino superior que serão futuros professores e avaliadores. Subsidiariamente esperamos que o estudo forneça dados e informações que permitam uma melhor compreensão dos aspectos envolvidos no processo de avaliação da aprendizagem e que sirvam de elementos para uma reflexão mais acurada sobre a prática docente, fornecendo um conjunto de informações relevantes, tanto do ponto de vista da reflexão teórica quanto do ponto de vista da prática educativa.

Palavras-chaves: Aluno; Professor; Avaliação; Processo.

\begin{abstract}
This article presents the application of a participative evaluation proposal in a Literature and Arts Degree course and of an inquiry which investigated the opinion of university students regarding the positive and negative aspects of such evaluation and which are the issues that make a student's presentation to be considered good or bad. The investigation, developed according to the orientations of the qualitative focus, had as fundamental aim to identify, characterize and analyze the meanings and practices of the learning evaluation, according to the university student's perspective, who will be the future teachers and evaluators. Subsidiarily we expect that this study is able to provide information and data that allow a better comprehension of the aspects involved on the learning evaluation process and that these can be used as elements for a more accurate reflection about teaching, providing a series of notable information, both from the theoretical reflection and the educational point of view.
\end{abstract}

\footnotetext{
1 Professora Doutora do Curso de Letras na UFTM - Universidade Federal do Triângulo Mineiro. araujokappel@terra.com.br
} 


\begin{tabular}{|l|l|l|l|l|l|l|}
\hline InterteXto & Uberaba & UFTM & $\begin{array}{l}\text { v. 2 } \\
\text { n. 3 }\end{array}$ & p. 14-35 & 2009- jan. / jun. & ISSN 1981-0601 \\
\hline
\end{tabular}

Key-words: Student; Teacher; Evaluation; Process.

\section{Introdução}

O processo de ensino-aprendizagem, nos últimos anos, sofreu mudanças consideráveis. Antes, em um processo unilateral, o professor se colocava como detentor, possuidor e fonte de conhecimento e o aluno, em atitude passiva, como recebedor desse conhecimento inquestionável emitido pelo professor. Tal posicionamento nos leva a algumas premissas equivocadas como: sem a aula do professor e a transmissão de seu conhecimento não pode haver crescimento do aluno nem aprendizado; o aluno nunca supera o conhecimento do professor.

Com o avanço das ciências, o acesso rápido a informações pela sociedade em geral, o professor perdeu seu posto de detentor majoritário do conhecimento. Sendo assim, o lugar do professor no processo ensinoaprendizado passa a ser como a de um mediador do conhecimento, um orientador, co-autor da gestão da aprendizagem do aluno.

Apesar da característica contemporânea dessa nova filosofia, percebemos que o método utilizado para levar o conhecimento pela maioria dos professores ainda é a fala do professor e a passividade do aluno. Highet (1950), em sua obra $A$ arte de ensinar afirma que, no ensino formal, existem três momentos distintos: a preparação das aulas, a comunicação do conhecimento e a avaliação do aprendizado. Considera a comunicação do conhecimento como fundamental para a formação do aluno, podendo o professor usar três métodos para comunicar este conhecimento: aula expositiva, na qual o professor fala e os alunos ouvem; arguição em que os alunos estudam antecipadamente e o professor verifica por meio de perguntas ou seminários se os alunos leram e compreenderam o texto ou assunto indicado; método tutorial em que o professor orienta, instiga a aprendizagem do aluno. Sócrates é considerado o expoente desse método, pois propunha 


\begin{tabular}{|l|l|l|l|l|l|l|}
\hline InterteXto & Uberaba & UFTM & $\begin{array}{l}\text { v. 2 } \\
\text { n. 3 }\end{array}$ & p. 14-35 & 2009- jan. / jun. & ISSN 1981-0601 \\
\hline
\end{tabular}

questões e convidava os discípulos a respondê-las. Nesse método, o aluno passa a ter voz e, apesar de menos experiente que o professor, é tão competente quanto ele.

Para nós, tão importante quanto a comunicação do conhecimento é a avaliação do processo ensino-aprendizagem. Ela não é um apêndice independente do referido processo (está nesse processo) e exerce um papel específico em relação ao conjunto de componentes que integram o ensino como um todo (está num sistema). Muitas perguntas acerca da avaliação do aluno são levantadas: "Como atribuir notas aos alunos? Como fazer para que essas notas representem o desempenho real do aluno?" "Que abordagem avaliativa devemos adotar para a melhoria do ensino?" "Que aspectos metodológicos devem ser considerados no planejamento do ensino e na avaliação da aprendizagem?" "Deve-se abolir a nota do processo ensinoaprendizagem?" "Deve-se avaliar atitudes?" " Deve-se avaliar por meio de provas apenas, provas e trabalhos ou provas, trabalhos, participação e outros?"

As funções da avaliação na educação são potencialmente duas: o diagnóstico e a classificação. Da primeira, supõe-se que permita ao professor e ao aluno detectar os pontos fracos deste e extrair as consequências pertinentes sobre onde colocar, posteriormente, a ênfase no ensino e na aprendizagem. A segunda, classificação, tem por efeito hierarquizar, classificar e aprovar ou reprovar os alunos. Verifica-se, na prática, que a educação prega em parte a avaliação com base na primeira função, mas a emprega fundamentalmente para a segunda, conforme diz Luckesi (1995).

Já no entendimento da avaliação como parte integrante do Planejamento do Processo de Ensino - Aprendizagem, esse autor apresenta três funções: Diagnóstica, Formativa e Somativa.

A primeira tem por finalidade realizar uma sondagem de conhecimentos e experiências já disponíveis no aluno, bem como a existência de pré requisitos necessários à aquisição de um novo saber. 


\begin{tabular}{|l|l|l|l|l|l|l|}
\hline InterteXto & Uberaba & UFTM & $\begin{array}{l}\text { v. 2 } \\
\text { n. 3 }\end{array}$ & p. 14-35 & 2009- jan. / jun. & ISSN 1981-0601 \\
\hline
\end{tabular}

A função formativa tem por finalidade proporcionar o feedback (retroalimentação) para o professor e para o aluno, durante o desenvolvimento do processo ensino - aprendizagem. Propicia aos envolvidos (professor / aluno) a correção de falhas, esclarecimentos de dúvidas e estímulo a continuação do trabalho para alcance do objetivo.

A última, função somativa, tem o propósito de oferecer subsídios para o registro das informações relativas ao desempenho do aluno. Considerando que a função somativa da avaliação visa proporcionar uma medida que poderá ser expressa em uma nota ou conceito sobre o desempenho do aluno, entendemos que a mesma acontecerá ao final de cada unidade de ensino ou ao final de cada bimestre ou ainda no final do ano ou semestre letivo, segundo o Regimento Interno de cada instituição.

Interessa-nos abordar nesta análise específica, o que no curso de Letras e na IES em foco é proposto acerca da avaliação e prática docente em seu Projeto Pedagógico.

\section{A avaliação no Projeto Pedagógico do Curso de Letras da UFTM}

Segundo o Projeto Pedagógico do Curso de Letras da UFTM, o curso deve ser o lugar para se aprender a refletir a respeito de fatos linguísticos e literários. O aluno deve desenvolver habilidades para analisar, descrever e explicar esses fatos não de forma empírica, mas com competência teórica e reflexão crítica, fundamentados teórica e metodologicamente. A avaliação não pode se constituir em um anexo, pois é tudo o que diz respeito ao processo e está em um contínuo trabalho de integração regido por modos e processos de aprendizagem, para ser o que é e para transformar-se no que virá a ser.

Por compreender que a avaliação da aprendizagem é um mecanismo subsidiário do planejamento e da execução, ela só faz sentido na medida em que serve para o diagnóstico da execução e melhoria dos resultados. A perspectiva dessa avaliação pretende, essencialmente, opor-se ao modelo do 


\begin{tabular}{|l|l|l|l|l|l|l|}
\hline InterteXto & Uberaba & UFTM & $\begin{array}{l}\text { v. 2 } \\
\text { n. 3 }\end{array}$ & p. 14-35 & 2009- jan. / jun. & ISSN 1981-0601 \\
\hline
\end{tabular}

"transmitir-verificar-registrar" e evoluir no sentido de uma ação reflexiva e desafiadora do educador, com vista a contribuir, elucidar e favorecer a troca de idéias entre e com seus alunos. Isso caracteriza um movimento de superação do saber transmitido a uma produção de saber enriquecido, construído a partir da compreensão dos fenômenos estudados.

A adoção de uma avaliação formativa qualitativa e não-classificatória visa propiciar a abordagem de uma dimensão participativa no processo de avaliação, na qual os alunos, reconhecidos como partícipes legítimos do processo de ensino-aprendizagem, devem ser escutados em suas expectativas, acolhidos em suas carências e estimulados em suas curiosidades, além de incluídos na comunidade investigativa e deliberativa. Os instrumentos de avaliação adotados pelos professores devem cumprir a finalidade de poder diagnosticar o uso funcional e contextualizado dos conhecimentos dos alunos em processo de formação.

O Projeto afirma que não há como pensar em avaliação sem pensar em co-participação da comunidade discente. Sob esse enfoque, o educando constrói o seu conhecimento e a avaliação se apresenta como mediadora entre o saber construído e a reflexão sobre esse saber.

A Universidade Federal do Triângulo Mineiro à qual o curso de Letras está subordinado, entende, por meio de seu Estatuto e Regimento Geral que, para ser coerente com os princípios da formação profissional proposta, é necessário implementar uma avaliação da aprendizagem que se caracterize por ser uma prática humanista/democrática. Nesse sentido, realiza uma ação coletiva e consensual, investigativa e reflexiva, diante da qual professores e alunos assumem uma postura cooperativa, crítica e responsável.

As estratégias utilizadas para as avaliações serão as mais diversas, considerando a natureza de cada unidade e a liberdade de cada docente. Portanto, poderão ser empregados, como recurso de avaliação, os debates, os grupos de trabalho, a análise crítica de textos e vídeos, as oficinas, as pesquisas, os portfólios, os seminários, dentre outros. 


\begin{tabular}{|l|l|l|l|l|l|l|}
\hline InterteXto & Uberaba & UFTM & $\begin{array}{l}\text { v. 2 } \\
\text { n. 3 }\end{array}$ & p. 14-35 & 2009- jan. / jun. & ISSN 1981-0601 \\
\hline
\end{tabular}

No Projeto Pedagógico do Curso de Letras está explícito que os critérios de avaliação estabelecidos na Universidade consideram a freqüência e o aproveitamento do aluno durante o período letivo. Além desses critérios, deverá ser garantida nos planos de ensino de cada disciplina, pelo professor responsável, a operacionalização dos recursos de avaliação para aferir a freqüência e o aproveitamento de estudos do aluno. Sendo assim, a proposta de avaliação será definida nos Planos de Ensino de cada professor.

\section{Análise de uma proposta de avaliação no Plano de Ensino de Língua Portuguesa IV}

Para a disciplina de Língua Portuguesa IV - Morfologia e Morfossintaxe, pensando que a metodologia da avaliação dos alunos não deve se restringir a um único momento; que ela deve perpassar todo o processo de aprendizagem, tendo claro o perfil do aluno que se quer formar; que é necessário identificar as dificuldades e valorizar as competências dos alunos para que o professor possa atuar e intervir, levando não só em consideração os conhecimentos, como as habilidades, seus valores e atitudes, o Plano de Ensino dessa disciplina, entregue aos alunos no primeiro dia de aula, definiu a avaliação da seguinte forma:

A avaliação deverá ser um processo contínuo, em que 30 pontos definidos pelo Regimento da Universidade - serão atribuídos ao longo do semestre, com as seguintes estratégias de avaliação:

a) coletiva/oral junto aos alunos para avaliação das aulas e do progresso dos alunos;

b) individual, de forma processual, em que se observa a participação nas atividades, a produção e o desenvolvimento do aluno nas aulas;

c) individual escrita, em dias específicos, para diagnosticar os avanços e as dificuldades dos alunos; 


\begin{tabular}{|l|l|l|l|l|l|l|}
\hline InterteXto & Uberaba & UFTM & $\begin{array}{l}\text { v. 2 } \\
\text { n. 3 }\end{array}$ & p. 14-35 & 2009- jan. / jun. & ISSN 1981-0601 \\
\hline
\end{tabular}

d) grupal oral e escrita, com desenvolvimento de pesquisa, em todo processo: desde o planejamento de atividades até a apresentação escrita e oral.

e) final individual e participativa para mensurar a eficácia dos objetivos trabalhados, valorizar a experiência profissional e a aptidão de cada aluno.

No final do semestre, essa "avaliação individual participativa" será apresentada por cada aluno, segundo a escolha do tema e da maneira a ser trabalhado pelo aluno sob orientação da professora (vide anexa a cópia da ficha de avaliação individual e participativa entregue ao aluno junto ao Plano de Ensino no primeiro dia de aula). Para tanto, o aluno deverá entregar na primeira semana do segundo bimestre a síntese da proposta de trabalho que ele escolher.

São explicados, também, os aspectos apresentados abaixo a serem observados pelo professor tanto na parte escrita quanto na apresentação oral para avaliação do trabalho.

$\mathrm{Na}$ parte escrita são analisados os itens relacionados abaixo, adequando-os à escolha do aluno se atividade de ensino, quando está relacionado à transmissão e à socialização do conhecimento; de pesquisa ao produzir conhecimento; ou atividade de extensão, quando abre espaço para a aplicação do conhecimento nas demandas sociais.

\section{1- Identificação}

2- Tema

3- Introdução

Justificativa

Objetivos

Hipóteses

Pergunta de pesquisa /estudo

4. Quadro teórico de referência

4.1- Princípios básicos

5- A pesquisa/estudo

5.1 Local

5.2 O corpus

5.3 Metodologia 


\begin{tabular}{|l|l|l|l|l|l|l|}
\hline InterteXto & Uberaba & UFTM & $\begin{array}{l}\text { v. 2 } \\
\text { n. 3 }\end{array}$ & p. 14-35 & 2009-jan. / jun. & ISSN 1981-0601 \\
\hline
\end{tabular}

5.4 Cronograma de execução

5.5 Público-alvo

6- Análise

7- Considerações finais

8- Bibliografia / Referências

Anexos - se houver

Já na parte oral, atentando para os aspectos de uma apresentação oral em situação formal, são observados os seguintes aspectos:

1- Condições de produção - situação de elaboração e de comunicação; definição da apresentação; conhecimento geral do assunto; domínio do assunto para responder aos questionamentos da turma; adequação do assunto ao público-alvo.

2- Construção interna - organização da apresentação abertura da apresentação; introdução ao tema; apresentação do plano a ser desenvolvido; desenvolvimento do tema; recapitulação; conclusão; encerramento.

3- Articulação do texto - encadeamento de idéias; elementos de coesão; continuidade de um segmento para outro - progressão textual; exemplos - uso de aspectos verbais e não-verbais; repertório linguístico; expressões e estruturação úteis.

4- Uso de aspectos não verbais para enriquecimento da apresentação - olhar, expressividade facial e sonora; gestos; música; imagens; recursos utilizados; interação com o público.

Após a entrega da ficha (Anexo), quando já se venceram $60 \%$ da carga horária, o professor lê as propostas dos alunos e devolve as fichas com as observações pertinentes, sugestões e propostas de alteração e/ou complementação. No final do semestre, em data e hora agendada, em média 30 minutos para cada aluno, acontecem as apresentações dos trabalhos para a classe e a entrega do trabalho escrito para a professora. O professor avalia oralmente a apresentação do aluno, dá-lhe uma nota referente às partes escrita e apresentação oral e o aluno se auto-avalia. As notas são somadas e divididas para obtenção da média. 


\begin{tabular}{|l|l|l|l|l|l|l|}
\hline InterteXto & Uberaba & UFTM & $\begin{array}{l}\text { v. 2 } \\
\text { n. 3 }\end{array}$ & p. 14-35 & 2009- jan. / jun. & ISSN 1981-0601 \\
\hline
\end{tabular}

Para nossa verificação se a proposta de avaliação atingiu seus propósitos, numa interação entre professor e aluno, julgamos necessário fazer uma pesquisa junto aos alunos que passaram por essa avaliação.

Aplicamos um questionário, no final do segundo semestre de 2008, nos alunos que se dispuseram a participar, sem necessidade de identificação. Foram ao todo vinte alunos, sendo dez (50\%) da turma de Língua Portuguesa $\checkmark$ que já haviam passado por essa avaliação em dois semestres: em LP IV e LP $\vee$, e dez alunos que participaram dessa proposta pela primeira vez em LP IV.

O procedimento foi empírico porque advém da experiência, ou seja, da observação e tratamento experimental dos fatos, e comparativo ao estudar as diferenças e semelhanças entre as respostas fornecidas pelos alunos, com a finalidade de verificar similitudes e explicar divergências. Esta pesquisa é quantitativa, quando fazemos um levantamento das respostas obtidas, identificando as predominantes ou não, e quando computamos a proporcionalidade nas respostas dadas. É de natureza qualitativa, utilizando-se da análise textual e interpretativista como ferramenta para verificar a reflexão e a criticidade das respostas ao avaliar a avaliação e o resultado fornecido pelas respostas.

As questões apresentadas aos alunos no questionário aplicado foram divididas em dois focos: a avaliação da proposta de avaliação e a avaliação das apresentações dos colegas. Foram duas perguntas para cada foco:

Em relação à "avaliação individual participativa" foram feitas as seguintes perguntas: quais os pontos positivos e negativos desse tipo de avaliação.

Destacaremos, a seguir, para análise dessa proposta, alguns itens acerca do ponto de vista do professor proponente dessa avaliação.

\section{Reflexões acerca da iniciativa desta proposição de "Avaliação Individual Participativa"}




\begin{tabular}{|l|l|l|l|l|l|l|}
\hline InterteXto & Uberaba & UFTM & $\begin{array}{l}\text { v. 2 } \\
\text { n. 3 }\end{array}$ & p. 14-35 & 2009- jan. / jun. & ISSN 1981-0601 \\
\hline
\end{tabular}

Para nós, falar em Educação Superior, em especial os cursos de Licenciatura, pressupõe a formação de um profissional que deva estar referenciada às relações sociais em que a dinâmica da sociedade aponta a necessidade de a educação enfrentar novos desafios. Para Tedesco (2003), o primeiro desafio se situa num dos pilares da educação do futuro e diz respeito ao aspecto cognitivo, ou seja, às formas como os indivíduos se apropriam do conhecimento/aprendizagem e, nesse sentido, concordamos: a escola precisa mudar suas características tradicionais e despertar no estudante a necessidade de "aprender a aprender".

Com a proposta de tentar superar as limitações da educação tradicional no que se refere ao sistema de avaliação, pensamos em propor estratégias diversificadas que estimulassem a aprendizagem ativa como, por exemplo, o relacionamento dos temas estudados na disciplina com as demais interdisciplinaridade e com a experiência de vida dos alunos; o desenvolvimento da pedagogia problematizadora; a utilização da relação dialógica entre o aluno e o contexto-social em que está inserido; o envolvimento do aluno em processos de aprendizagem em que ele irá propor uma prática, realizá-la e apresentar os resultados, em um processo de autoaprendizagem, promovendo a interdisciplinaridade e a indissociabilidade entre ensino, pesquisa e extensão.

Pensando em uma avaliação que valorize os saberes dos alunos, o entusiasmo, a curiosidade, a autonomia, a iniciativa, o aprender a pensar para pensar o novo propusemos, então, a uma "avaliação individual participativa", amparada nas propostas de Armstrong (2001, p. 217) (Anexo).

Nessa avaliação, o professor será apenas um mediador pedagógico, que estimulará a análise e reflexão do aluno acerca de um determinado tema escolhido pelo próprio aluno, sustentado no conceito de ação mediada (VYGOTSKI, 1998), para quem o processo se estabelece quando duas ou mais 


\begin{tabular}{|l|l|l|l|l|l|l|}
\hline InterteXto & Uberaba & UFTM & $\begin{array}{l}\text { v. 2 } \\
\text { n. 3 }\end{array}$ & p. 14-35 & 2009- jan. / jun. & ISSN 1981-0601 \\
\hline
\end{tabular}

pessoas cooperam em uma atividade (inter-pessoal), possibilitando uma reelaboração (intra-pessoal), situação perfeitamente possível nessa avaliação.

O aluno tem autonomia de escolha dos aspectos temáticos, de enfoque, didáticos, científicos e de gestão de seu próprio trabalho e é avaliado pelo professor, pelos alunos e por ele mesmo, tornando a autonomia indissociável da avaliação em um processo de modernização da clássica avaliação.

Esse tipo de avaliação participativa pode oportunizar o aprofundamento em atividades de ensino, quando está relacionado à transmissão e à socialização do conhecimento; em atividades de pesquisa que produz o conhecimento; em atividades de extensão, quando abre espaço para a aplicação do conhecimento nas demandas sociais.

Ao propor esse tipo de avaliação, pensamos que, consequentemente, estaremos abrindo um espaço à interdisciplinaridade quando há a proposta de interação entre disciplinas, num processo que pode ir da simples comunicação de idéias até a integração recíproca de finalidades, objetivos e outros no processo de elaboração do conhecimento. Essa prática transcende o pensamento linear por flexibilizar os limites disciplinares, mostrando que os saberes não são específicos, dissociados ou hierarquizados em importância.

Quando, ao final do semestre, cada aluno apresenta o seu trabalho nas mais diversas formas, provoca uma articulação de saberes científicos com a sensibilidade a partir da autonomia do estudante para a proposição não só de temáticas interdisciplinares para a produção de conhecimentos, como também por meio das técnicas de que dispõe e que domina.

O professor não se sente o dono do saber a ser transmitido, mas aquele que provoca relações solidárias em situações de aprendizagem diferentes.

Tais situações de aprendizagem incluem os processos de formação da identidade do próprio aluno enquanto docente que, a partir da experiência de apresentar um tema, uma pesquisa, um trabalho de extensão um conhecimento adquirido, reflete acerca de seus papéis e atribuições, transformando suas práticas. 


\begin{tabular}{|l|l|l|l|l|l|l|}
\hline InterteXto & Uberaba & UFTM & $\begin{array}{l}\text { v. 2 } \\
\text { n. 3 }\end{array}$ & p. 14-35 & 2009- jan. / jun. & ISSN 1981-0601 \\
\hline
\end{tabular}

O papel do professor é de propor a oportunidade de concretização da iniciativa do aluno, provocando-o a ser o autor de sua própria busca de conhecimento, por meio da qual se processam relações igualitárias e dialógicas. Dessa forma, há uma reconfiguração dos lugares instituídos de "aluno" e de "professor" em prol da consecução de ensino-aprendizado individuais, envolvidos por ações coletivas que se pautam pelo protagonismo.

\section{Como os alunos avaliaram a "Avaliação Individual Participativa"}

De acordo com o que já foi dito, os alunos receberam um questionário acerca de dois aspectos: avaliação das apresentações dos alunos e acerca da avaliação em si.

Em relação às apresentações dos colegas de que mais gostaram, $55 \%$ (cinqüenta e cinco pro cento) dos entrevistados disseram que foram as que os alunos/professores tiveram postura segura ao apresentar 0 trabalho $e$ conseguiram explicar de maneira clara, conquistando a atenção dos ouvintes.

Vinte e cinco por cento destacaram a importância da análise de diferentes materiais didáticos e métodos de ensino, que será uma atividade constante do professor, e a abordagem interdisciplinar, ao comparar a língua portuguesa com a língua estrangeira ou com a literatura.

Outros aspectos interessantes foram apontados por quinze por cento dos entrevistados ao afirmar que foi boa a apresentação que oportunizou:

* Criar, unir teoria e prática - apresentar o conteúdo de forma lúdica com utilização de vários recursos - principalmente tecnológico, intertextualidade, referências de livros, gramáticas, sites, músicas, filmes e propor exercícios de fixação no final;

* Conteúdo interessante e abordagem adequada;

* Combinação entre estética, criatividade, emoção e conteúdo com atividades interessantes e possíveis de serem desenvolvidas pelo professor em sala de aula, despertando um olhar diferente sobre o ensino da gramática; 


\begin{tabular}{|l|l|l|l|l|l|l|}
\hline InterteXto & Uberaba & UFTM & $\begin{array}{l}\text { v. 2 } \\
\text { n. 3 }\end{array}$ & p. 14-35 & 2009- jan. / jun. & ISSN 1981-0601 \\
\hline
\end{tabular}

* Análise de questões de língua portuguesa em vestibular, nas escolas de Ensino Médio, ENEM e em concursos públicos com comentários pertinentes o que resultou uma variedade interessante de material e a reflexão acerca de como ensinar a língua tendo o foco em seu funcionamento;

* Conteúdo interessante, do qual não se tinha conhecimento ou pouco conhecimento;

* Os resultados de uma pesquisa de campo que mostrou diversificadas realidades de escolas de Ed. Básica, apontando as diferenças que os alunos irão encontrar na profissão, quando forem professores.

Outros aspectos importantes também foram citados por alguns como: o uso de imagens na apresentação, unindo linguagem verbal e não verbal tão complementares na vida atual; a percepção de que um mesmo assunto pode ser tratado de maneira diferenciada, com aprofundamento de estudos, o que proporcionou uma visão melhor; a aplicação do conhecimento gramatical e linguístico possibilitou uma apresentação que aproximou o saber técnico, científico ao nível do aluno da Educação Básica.

Em relação às apresentações de que menos gostaram, trinta e cinco por cento dos entrevistados apontaram para as que demonstraram insegurança na hora de falar, falta de didática (leituras extensas na hora da apresentação, sem explicação clara), de desenvoltura e de postura adequada do aluno/professor; falta de domínio do conteúdo ao apresentar análises erradas; focalização em conteúdo que não é específico da disciplina; as que demonstraram falta de preparação do aluno/professor, pois o material estava confuso, sem organização e sem sequência.

Outros pontos interessantes, que tornam uma apresentação ruim, foram levantados por alguns:

* Assunto apresentado com pouca coisa a ser acrescentada, realçada;

* Falta de contextualização do tema, sem levar à reflexão sobre a importância do uso da linguagem; 


\begin{tabular}{|l|l|l|l|l|l|l|}
\hline InterteXto & Uberaba & UFTM & $\begin{array}{l}\text { v. 2 } \\
\text { n. 3 }\end{array}$ & p. 14-35 & 2009- jan. / jun. & ISSN 1981-0601 \\
\hline
\end{tabular}

* Aula não apropriada para a Educação Básica ou Ensino Superior, conforme direcionamento proposto pelo aluno-professor;

* Apresentação do conteúdo da norma culta com crítica preconceituosa, jocosa em relação aos falantes de variação não padrão;

* A que não teve muito trabalho em pesquisar, apenas copiou apresentações de sites da internet.

Em relação à "Avaliação Individual Participativa" os alunos responderam duas questões para apontar os aspectos negativos e os positivos desse tipo de avaliação.

Quarenta por cento dos alunos apontaram, como ruim, a utilização de grande número de aulas por conta de apresentações o que fez reduzir o tempo para que o professor pudesse ministrar aulas, já que ele é que tem o conhecimento consolidado; a fuga ao tema em algumas apresentações de alunos por não terem seguido as orientações: no início do segundo bimestre, apresentar ao professor a proposta para ser analisada; a existência da autoavaliação, alegando que alguns alunos não sabem se avaliar - uns mereciam nota máxima e não se deram; outros mereciam nota baixa e se deram boas notas, avaliando de modo desonesto ou com falta de senso crítico, dando-lhe a nota que precisava e não a que merecia.

Uma porcentagem menor, quinze por cento, apontou que alguns alunos não prestaram atenção nas apresentações dos colegas, apesar de tanto esforço e trabalho para conseguir fazer a apresentação e que há falta de domínio para falar em público.

Outros pontos foram citados por poucos: um ou dois alunos:

* Devido à variedade e quantidade de trabalhos, apresentados em dias diferentes, fica difícil para o professor dar uma nota logo após a apresentação de cada um, de forma justa. (Esta crítica foi acatada pela professora e a nota passou a ser dada após a conclusão de todas as avaliações, oportunizando uma revisão da nota, antes de torná-la pública);

* Como a escolha é do aluno, surge apresentação de temas pouco importantes; 


\begin{tabular}{|l|l|l|l|l|l|l|}
\hline InterteXto & Uberaba & UFTM & $\begin{array}{l}\text { v. 2 } \\
\text { n. 3 }\end{array}$ & p. 14-35 & 2009- jan. / jun. & ISSN 1981-0601 \\
\hline
\end{tabular}

* Diante de inúmeras opções de trabalho sugeridos pela professora, inicialmente, fica difícil escolher o que apresentar;

* Uma nova maneira de avaliar deixa o aluno inseguro quanto ao assunto, a forma de trabalhar e a avaliação de todos;

* Ser individual - duas cabeças pensam melhor em caso de criatividade e segurança, pois, quando a escolha é do aluno, a responsabilidade e a cobrança são maiores.

* Ao escolher aquilo de que mais gosta não exercita os conteúdos que tem mais dificuldade;

* Senso crítico da professora ao avaliar oralmente as apresentações inibe o aluno.

* Dificuldades de delimitar o assunto dentro do prazo dado;

* As apresentações em língua estrangeira não estudada pelo aluno ${ }^{2}$ causa desatenção;

Em relação aos pontos positivos percebidos pelos alunos na "avaliação individual participativa", 65\% (sessenta e cinco por cento) responderam que ela prepara o aluno para a profissão - regência, para a participação em eventos científicos e culturais, para apresentação em seminário e para falar em público; respeita a aptidão, domínio e interesse de cada aluno em um assunto dentro da disciplina e do curso, podendo fazer a interdisciplinaridade, com domínio e prazer, além de facilitar a contextualização e oferecer uma diversidade interessante; oportuniza ao aluno o uso de recursos tecnológicos diferentes ou de materiais de que tem domínio e segurança ou que seja mais próximo do interesse do aluno da Educação Básica; maior autonomia do aluno sobre seus estudos escolhendo o tema, a forma de apresentação e os meios de que dispõe ou domina, além de não ter padrões pré-estabelecidos de pesquisa.

Vinte e cinco por cento apontaram como positivo a diversidade e riqueza dos temas apresentados por todos, podendo o aluno/professor ser criativo e

\footnotetext{
${ }^{2}$ As aulas de Língua Portuguesa são ministradas em conjunto para as turmas com habilitação em Espanhol e em Inglês.
} 


\begin{tabular}{|l|l|l|l|l|l|l|}
\hline InterteXto & Uberaba & UFTM & $\begin{array}{l}\text { v. 2 } \\
\text { n. 3 }\end{array}$ & p. 14-35 & 2009- jan. / jun. & ISSN 1981-0601 \\
\hline
\end{tabular}

original; a avaliação ser processual e diversificada, incluindo a autoavaliação já que, muitas vezes, na apresentação, o aluno/professor não consegue mostrar tudo que aprendeu, além de ele aprender avaliar ele mesmo para depois avaliar seus futuros alunos; a preparação de apresentações cronometrando o tempo que Ihe foi permitido usar; as intervenções da professora durante as apresentações no que diz respeito a esclarecer dúvidas e complementar o conteúdo abordado, engrandecendo as apresentações; o aluno pode escolher o tema e ir se preparando, organizando e planejando desde o início do semestre, o que the dá oportunidade de aperfeiçoamento do trabalho; a oportunidade de o aluno se envolver em pesquisa ou desenvolver seu próprio trabalho, com espírito de iniciativa.

Outros pontos positivos dessa avaliação foram apontados por apenas três, dois ou um aluno:

* Aprendizagem. Há aprendizado do aluno em todo o processo tanto na elaboração e apresentação de seu trabalho quanto na assistência às apresentações dos colegas;

${ }^{*}$ As aulas ficam mais participativas;

* A turma aprende mais assistindo aos variados tipos de trabalho;

* Experiência de avaliação diferente do que há habitualmente desperta interesse do aluno em relação ao que fazer, como realizar um trabalho, uma pesquisa ou como ministrar uma aula ao assistir ao que o outro fez e ao preparar seu próprio fazer;

* Oportuniza a desenvoltura do aluno para a prática docente e o domínio da fala em público;

* Todas apresentações sejam boas ou ruins nos trazem aprendizado para a vida profissional acerca do que devemos fazer e do que não devemos fazer como professores;

* Dá liberdade para que várias habilidades dos alunos se manifestem, o que Gardner chama de inteligências múltiplas;

* Assimilação da matéria de forma interessante e variada; 


\begin{tabular}{|l|l|l|l|l|l|l|}
\hline InterteXto & Uberaba & UFTM & $\begin{array}{l}\text { v. 2 } \\
\text { n. 3 }\end{array}$ & p. 14-35 & 2009 - jan. / jun. & ISSN 1981-0601 \\
\hline
\end{tabular}

* Aquisição de novas abordagens para futuros trabalhos e ampliação da aplicabilidade das teorias;

* Os alunos ficam mais interessados em aprender e descobrem suas próprias aptidões e dons.

* Apresentações puderam ser levadas para fora do ambiente da sala de aula como reapresentação em eventos científicos e culturais ou até ser o início de um TCC (Trabalho de Conclusão de Curso);

* Poder unir paradoxalmente o que o aluno gosta (Literatura) com o que não gosta muito (Morfologia).

* Poder antecipar a heterogeneidade das salas de aula - nossos futuros alunos

- com a heterogeneidade da nossa própria sala, ao assumir a postura de professor;

* A permanência dos alunos na sala para assistir às apresentações dos colegas, devido às inúmeras formas de abordagem de um mesmo tema escolhido por mais de um aluno ou vários temas;

\section{Alguns comentários acerca das respostas dadas pelos alunos}

Como pudemos observar na avaliação dos próprios alunos envolvidos nesta prática, os pontos positivos acerca desse tipo de avaliação foram superiores aos negativos, se considerarmos a proporcionalidade de alguns aspectos e a quantidade de itens enumerados.

Os alunos reconhecem que, com essa avaliação, tornam-se partícipes do processo ensino-aprendizagem, que são instigados a assumir postura cooperativa, crítica, responsável e que são incentivados a investigar, deliberar e produzir, entretanto poucos não se sentem preparados para isso.

Eles foram capazes de perceber que as atitudes, a postura, a maneira segura de apresentar, fruto de preparação, planejamento, pesquisa e estudo influenciam muito para uma boa prática profissional. Ficou claro, também, que, 


\begin{tabular}{|l|l|l|l|l|l|l|}
\hline InterteXto & Uberaba & UFTM & $\begin{array}{l}\text { v. 2 } \\
\text { n. 3 }\end{array}$ & p. 14-35 & 2009- jan. / jun. & ISSN 1981-0601 \\
\hline
\end{tabular}

ao contrário, se o aluno-professor não planejar nem se preparar não será visto como um bom professor.

A autoavaliação foi elogiada e criticada, entretanto foi percebido que 0 mal não está na autoavaliação em si, mas na postura do aluno em se autoavaliar inadequadamente, dando-lhe a nota que precisa e não a que merece, postura essa negativa para um profissional ético que se pretende formar, ou uma nota aquém do que o aluno merece por timidez ou modéstia. Como a nota que o aluno se deu não é alterada, mas somada às que o professor dá, o aluno tem a oportunidade de refletir acerca de sua própria autoavaliação.

Percebemos que alguns itens foram apontados por uns como positivos e por outros, como negativos, mas os argumentos usados para a defesa do ponto de vista são fundamentais para nossa consideração.

Além disso, paradoxalmente, os alunos perceberam a importância da coconstrução de saberes, de se desenvolver a competência do aluno ao mostrar sua própria voz, mas, por comodismo ou costume, sentem falta das aulas ministradas pelo professor como transmissor de conteúdo, como a principal fonte de conhecimento.

As respostas dadas nos ajudaram a repensar muitos pontos e tenho certeza de que farão o leitor repensar a avaliação tradicional e esta proposta, pois não é fácil romper paradigmas nem (re)construir o novo.

\section{Considerações finais}

Ao realizarmos esta proposta, não pretendemos dar receitas de como avaliar, muito menos dar modelos a serem seguidos, mas sim, levantar fatos que parecem afetar a interação entre professor/aluno e aluno/aluno, facilitando ou dificultando o acompanhamento da aprendizagem.

A "Avaliação Individual Participativa" verifica a aprendizagem na formação educacional proporcionando ao aluno a oportunidade de ele ser o 


\begin{tabular}{|l|l|l|l|l|l|l|}
\hline InterteXto & Uberaba & UFTM & $\begin{array}{l}\text { v. 2 } \\
\text { n. 3 }\end{array}$ & p. 14-35 & 2009- jan. / jun. & ISSN 1981-0601 \\
\hline
\end{tabular}

pensador, o gestor de seu próprio conhecimento, sua própria aprendizagem, minimizando as dificuldades e qualificando as habilidades. Ao mesmo tempo que oportuniza a integração entre os sujeitos envolvidos, ela também abre espaço para os processos coletivos e diversificados de aprendizagem.

Dessa forma, esse tipo de avaliação foge da passividade dos alunos em que o professor tem a função de transmitir o conhecimento acabado e o aluno de assimilá-lo apenas, como algo cristalizado, pronto e acabado. Abre-se, assim, um espaço para a construção de novos saberes e para o desenvolvimento do domínio dos processos e métodos gerais e específicos de investigação, necessários à produção do conhecimento.

Portanto, pudemos constatar que esse tipo de avaliação, aplicada em cursos de Licenciatura, proporciona ao aluno uma vida acadêmica mais rica em experiência, maior aproveitamento do ensino e da capacidade de aprendizagem e de ensino como futuros professores, além de atender ao que o Projeto Pedagógico do Curso de Letras propõe em relação à avaliação: ser uma ação reflexiva, desafiadora, que supera o saber transmitido pelo professor ao produzir saberes enriquecidos.

\section{Referências}

ARMSTRONG, Thomas. Inteligências múltiplas na sala de aula. 2.ed. Porto Alegre: ARTMED, 2001, p. 217.

HIGHET, Gilbert. A arte de ensinar. São Paulo: Melhoramentos, s/d (copyright de 1950).

LUCKESI, Cipriano C. Avaliação da Aprendizagem Escolar. São Paulo: Cortez,1995.

TEDESCO, J.C. Los pilares de La educación Del futuro. Em: Debates de educación (2003: Barcelona) [ponencia em línea]. Fundación Jume Bofill; UOC. [Fecha de consulta: 05/05/2006]. HTTP://www.uoc.edu/dt/20367/index.html. 


\begin{tabular}{|l|l|l|l|l|l|l|}
\hline InterteXto & Uberaba & UFTM & $\begin{array}{l}\text { v. 2 } \\
\text { n. 3 }\end{array}$ & p. 14-35 & 2009- jan. / jun. & ISSN 1981-0601 \\
\hline
\end{tabular}

VYGOTSKI, L. S. A formação social da mente: o desenvolvimento dos processos psicológicos superiores. 6ed. São Paulo: Martins Fontes, 1998.

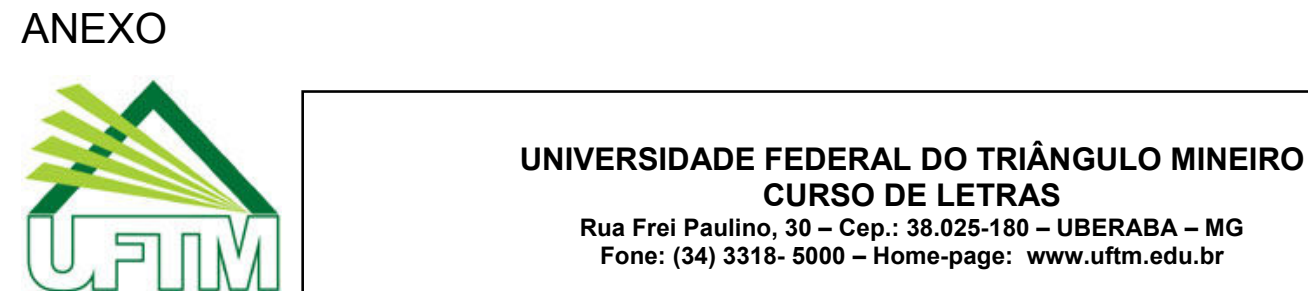

\section{AVALIAÇÃO INDIVIDUAL PARTICIPATIVA DE LÍNGUA PORTUGUESA IV - MORFOLOGIA \\ CURSO: LETRAS \\ SEMESTRE: $2^{\circ}$ de 2008}

DISCIPLINA: Língua Portuguesa IV - Morfologia do Português

PROF $^{a} .:$ Irma Beatriz Araújo Kappel

DATA:

PERÍODO: IV

\section{GRADUANDO (A):}

Esta avaliação, proposta para o final do semestre, será individual e participativa por oferecer opções de trabalho para que você escolha a que melhor lhe convier, levando-se em consideração a sua experiência profissional, seu interesse e sua aptidão.

Baseado(a) na ficha abaixo proposta por Armstrong $^{3}$ e em algumas sugestões específicas para o conteúdo de Morfologia elaboradas pela professora, escolha como deseja ser avaliado(a). Atente na variedade de instrumentos e linguagens que elas representam e na maneira adequada de apresentação, podendo ser, inclusive, em forma de Portfólio.

Como pré-requisito, leia as bibliografias básica e complementar do Planejamento de Ensino desta disciplina e as propostas dos seguintes artigos:

ROCHA, Maria Constança (Org.). Ensino Médio: os desafios da reforma. Belo Horizonte: SEE/MG, 2002, p.69-96. (Lições de Minas, v.16).

\footnotetext{
${ }^{3}$ ARMSTRONG, Thomas. Inteligências múltiplas na sala de aula. 2.ed. Porto Alegre: ARTMED, 2001, p. 217.
} 


\begin{tabular}{|l|l|l|l|l|l|l|}
\hline InterteXto & Uberaba & UFTM & $\begin{array}{l}\text { v. 2 } \\
\text { n. 3 }\end{array}$ & p. 14-35 & 2009 - jan. / jun. & ISSN 1981-0601 \\
\hline
\end{tabular}

FREITAS, J.E.; MOL, M.L.A.(Orgs.). Português: língua pátria, fator de identidade e resistência. Belo Horizonte: SEE/MG, 2000, p. 97-107. (Lições de Minas, v.8).

\section{FICHA DE INSCRIÇÃO DO ALUNO PARA "VERIFICAÇÃO DA APRENDIZAGEM", seguindo as Sugestões Gerais de Armstrong e Sugestões Específicas apresentadas pela professora}

Para mostrar que eu sei MORFOLOGIA eu gostaria de:
( ) fazer um relatório
( ) fazer um ensaio fotográfico
( ) criar uma série de esboços/diagramas
( ) montar um livro de recortes
( ) montar um experimento
( ) construir um modelo
( ) promover um debate ou discussão
( ) fazer uma demonstração ao vivo
( ) fazer um mapa mental
( ) criar um projeto ecológico
( ) produzir um vídeo
( ) montar um musical
( ) criar e desenvolver um projeto em grupo
( ) criar um rap ou uma música
( ) fazer um gráfico estatístico
( ) fazer uma apresentação interativa em
( ) ensinar o assunto a alguém
( ) manter um diário computador sobre o assunto
( ) coreografar uma dança
( ) dar uma palestra
( ) fazer uma simulação
( ) gravar entrevistas
( ) planejar um mural
( ) criar uma discografia baseada no assunto
( ) fazer um projeto diferente dos listados
( ) Elaborar ou revisar um jornal.
( ) Produzir uma página na internet.

( ) Criar textos publicitários utilizando recursos da estrutura e formação de palavras.

( ) Preparar uma aula acerca de um dos assuntos, aplicar em uma turma e apresentar os resultados.

( ) Analisar perguntas do ENEM, de vestibulares, de concursos, de avaliações governamentais ou de professores acerca de assuntos que envolvem questões morfológicas.

( ) Elaborar um paralelo acerca das explicações das classes de palavras e suas flexões entre gramáticas diferentes e entre o enfoque da Lingüística - Morfologia Lexical.

( ) Separar exercícios de livros didáticos dos Ensinos Fundamental e Médio acerca da Morfologia e avaliá-los.

( ) Elaborar uma avaliação deste conteúdo para uma série definida, aplicar e apresentar os resultados.

( ) Elaborar um jornal (artigos, notícias, propaganda...).

( ) Montar uma revista de história em quadrinhos.

( ) Redigir um artigo, após realização de pesquisa, para publicação em revista literária.

( ) Outra sugerida pelo aluno: 


\begin{tabular}{|l|l|l|l|l|l|l|}
\hline InterteXto & Uberaba & UFTM & $\begin{array}{l}\text { v. 2 } \\
\text { n. } 3\end{array}$ & p. 14-35 & 2009- jan. / jun. & ISSN 1981-0601 \\
\hline
\end{tabular}

$\overline{\text { Ficha a ser preenchida e devolvida para a professora na primeira semana }}$ do segundo bimestre:

Breve descrição do que eu pretendo fazer:

Assinatura do aluno:

Data:

Comentários/sugestões/indicações de leitura do Professor:

Assinatura do professor:

Data:

Da rotina desgastante e do esvaziamento progressivo, deve emergir o trabalho inovador do professor para se colocar como um desafio estimulante e realizador do significado de SER PROFESSOR.

Bom trabalho! Prof $^{a} D^{a}{ }^{a}$ Irma Beatriz Araújo Kappel 